\title{
DTW based Modulation Detection- Verification using Software Defined Radio
}

\author{
KHUSHBOO TERONPI, KANDARPA KUMAR SARMA, ARADHANA MiSRA \\ Electronics and Communication Enginnering, Gauhati University, Guwahati, INDIA \\ MANASJYOTI BHUYAN \\ Electronics and Communication Technology, Gauhati University, Guwahati, INDIA
}

\begin{abstract}
Modulation detection is one of the major tasks of an intelligent receiver in a software defined radio (SDR). It is an intermediate step between signal detection and demodulation. In this paper we present the modulation detection based on Dynamic Time Warping (DTW) algorithm. Here the types of modulation that we use are QPSK, 8-PSK, 16-QAM and 64-QAM. The whole test and verification has been done with the help of SDR platform. After the test and trials of all the modulation schemes, it is observed that DTW provides a good efficiency with the accuracy of $93.75 \%$.
\end{abstract}

Keywords-Modulation Detection, Dynamic Time Warping, Software Defined Radio (SDR).

Received: April 3, 2021. Revised: July 26, 2021. Accepted: August 5, 2021. Published: August 10, 2021.

\section{Introduction}

Wireless communication is one of the most developed areas in the communication field today. It is a technique of transferring data from one point to the other without using connections such as wires, cables or any physical medium. Wireless communications come with many advantages over wired communications. Some of them include the cost, mobility, ease of installation, reliability, etc. Even though the wireless communication has numerous advantages over wired communication, there are some aspects of wireless communication that makes the involved problem challenging and interesting. Software Define Radio (SDR) is an enabling technology that is useful in a wide range of areas within wireless systems. SDR is a radio communication system where major part of its functionality is mainly implemented by means of software in a personal computer or embedded system. Because of its re-configurability and reprogrammability property, SDR has replaced many analog components and hardwired digital devices. It has a wide range of applications some of which includes: decoding aircraft short messages, in police radio scanner, listening to Very High Frequency (VHF) amateur radio, scanning or cordless phones, detecting Global System for Mobile (GSM) signals, reversing engineering unknown protocol, etc. The initial development of SDR took place around 1970's. During that phase VLF radios were commonly used that has been based on Analog to Digital Conversion (ADC). These radios had connected to an 8085 microprocessor for transmission. Application of these systems has been used by ground forces of USA and Great Britain. Over the past decades tremendous changes to the system has been made, demonstrating more technical visibility to the SDR approach in the designing of radio equipment [1][2]. SDR is a radio communication transceiver system in which all the typical components of a communication system such as mixers, modulators/demodulators, detectors, amplifiers has been implemented through software rather than hardware [1]. This strategy is useful because a system that is consistent with more mobile communication standard can be developed. This can be accomplished using re-configurable hardware and swapping the software for various technologies [1].

\subsection{Relevant Literature Survey}

A wide range of implementations over SDR has been performed over past decades. Many techniques have been introduced throughout the years and have resulted in improved version of SDR, along with both advantages and disadvantages. This section shows some related works of researchers. In [1], a model of SDR has been developed using SIMULINK tool to implement in the field of IEEE 802.11 standard and the Bluetooth standard. This model has been developed by building various protocols of WLAN and the Bluetooth standards. Their basic transmission mode was carried out using a half convolution code using Nakagami channel model where as in [3] the implementation of SDR was carried out by reconfiguring the SDR platform using USRP and GNU radio. Here the concept of spectrum sensing has been used for detecting the available spectrum holes which are then used for establishment of the digital data communication link to transmit the digital data. The whole process has been carried out to enhance the spectrum utilization where the working frequency can be adjusted to other available frequency bands through SDR's reconfigurable capability which are necessary conditions to accomplish the popular cognitive radio. With the implementation of SDR although, the past works finds more method of implementing an SDR in analog modulation field, some of the works included the introduction of SDR in digital modulation field. In [2], an automatic switching of modulation method has been described which is used to reconfigure transceiver of SDR based wireless communication system. This flexibility will also translate adaptively, which is used in this work to optimize the throughput of a wireless network, operating under varying channel conditions. The work is robust and efficient with 
processing time overhead that will still allow the SDR to maintain its real-time operating objectives. Here AWGN channel has been used giving a threshold of $5 \mathrm{~dB}$ for the case study. In [8], it describes the design of modulator and demodulator software systems of SDR using MATLAB SIMULINK tool for different modulation techniques. Here simulation results have been used for verification of the results of designed SDR systems. In [7], analysis of different modulation techniques used for SDR has been described. It gives an idea of selection of modulation scheme depending on bit error rate (BER), signal to noise ratio (SNR), available bandwidth. In [9], a software platform with digital data communication capability has been proposed which included a platform consisting of Field Programmable Gate Array (FPGA) based on radio hardware and open source software modules.

In this paper we present the modulation detection based on Dynamic Time Warping (DTW) algorithm. Here, the types of modulation that we use are QPSK, 8-PSK, 16-QAM and 64-QAM. The work has been done on a SDR platform. After the test and trials of all the modulation schemes, it is observed that DTW provides a good efficiency with the accuracy of $93.75 \%$.

The remaining part of the paper is categorized as follows: In Section II, a brief overview on Dynamic Time Warping (DTW) is given. In Section III, we have elaborated the working of transmitter and receiver models for DTW based modulation detection. In Section III, the experimental observations under different test conditions are represented in tabulated form with brief elaboration. Section V concludes the paper with the discussion of future direction.

\section{An Overview on Dynamic Time Warping (DTW)}

Dynamic Time Warping (DTW) is one kind of algorithm that measures the similarities between two temporal sequences. Similar properties in signal can be detected using DTW, even if there is slight variation in the signal on one of the signal. In general, DTW is a method that is used to calculate an optimal match between two given sequences but with certain restrictions and rules:

- Every index from the first sequence must be matched with one or more indices from the other sequence, and vice versa.

- The first index from the first sequence must be matched with the first index from the other sequence (but it does not have to be its only match).

- The last index from the first sequence must be matched with the last index from the other sequence (but it does not have to be its only match).

- The mapping of the indices from the first sequence to indices from the other sequence must be monotonically increasing, and vice versa.

The optimal match is denoted by the match that meets all the constraints and rules and has the minimum cost, where the cost is calculated as the sum of absolute differences between their values for each matched pair of indices. The sequences are "warped" non-linearly in the time dimension to determine a measure of their similarity independent of certain non-linear variations in the time dimension. This sequence alignment method is often used in time series classification. DTW doesn't guarantee the triangle inequality to hold, although it measures a distance-like quantity between two given sequences. In addition to a similarity measure between the two sequences, a so called "warping path" is produced, by warping according to this path the two signals may be aligned in time.

\section{Proposed Work 3.1 Working Model}

The Fig.1 shows the transmitter model of modulation detection based on DTW. In the transmission part, first the bits are generated and then the bits are fed to the modulator for modulation. Simultaneously frame headers are also generated and modulated. Both of the modulated signals are added with frame headers. Frame headers perform synchronization. After the synchronization, pilot signal is inserted to the synchronized signal. The output signal is then filtered using Root Raised Cosine (RRC) filtering. RRC filter is used for performing matched filtering so that Inter-symbol Interference (ISI) is minimized. The filtered signals are then up-sampled to factor 8 . In the next stage the signals are again up-sampled to a factor of 1.5. The up-sampled signals are then passed through SDR Pluto through the transmitter antenna mounted on one side of the antenna.

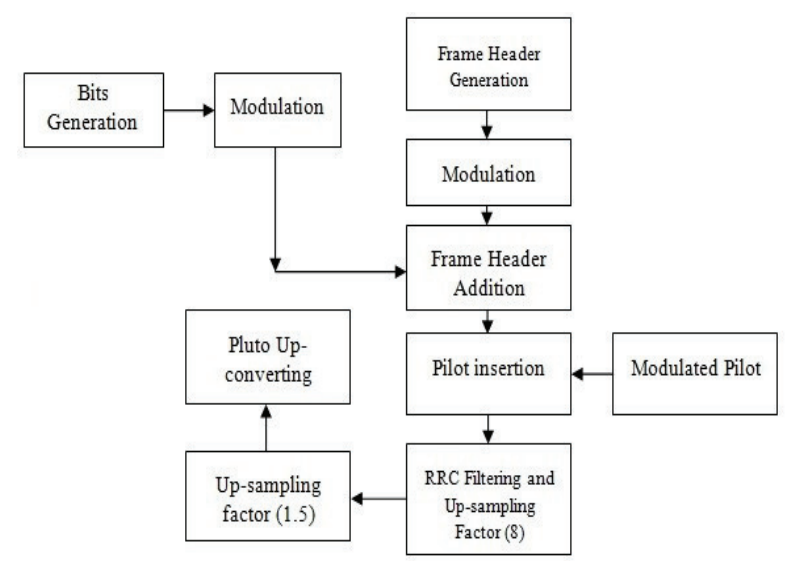

Fig. 1. Transmitter model for DTW based modulation detection.

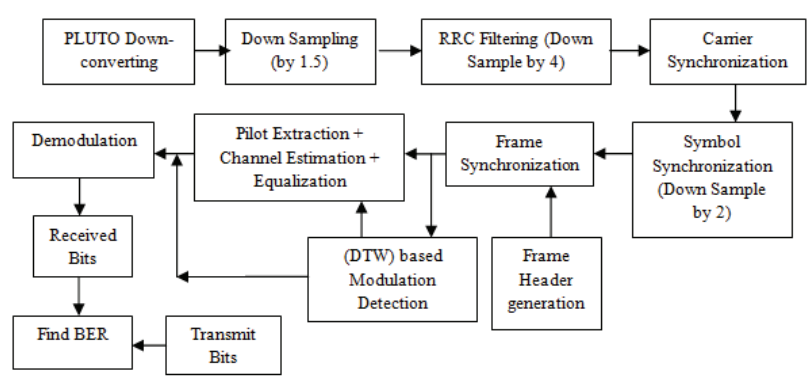

Fig. 2. Receiver model for DTW based modulation detection. 
In the receiver part, as shown in Fig.2, the receiver antenna, mounted on another side of the SDR hardware receives the signal and down converts it. The down converted signal is down-sampled by factor 1.5 and fed to the RRC filter where the signals are again down-sampled by factor 4 . The sampled signal is then passed through the carrier synchronization stage where both timing synchronization and carrier synchronization takes place. Timing synchronization determines the correct instants of time, at which to take samples of the incoming signal. In carrier synchronization, the receiver adapts the frequency and phase of its local oscillator with those of received signal. So this stage corrects the time and frequency of the signal. The next stage is symbol synchronization where signal is down-sampled by factor of 2. In this stage Gardner (non data aided) algorithm has been used to recover symbol timing phase. The next stage is the final stage of synchronization, which is the frame synchronization. It is used to estimate the start, validity and end of a frame. This is followed up by the modulation detection stage, where the type of modulation is detected before signal demodulation. The detection of the signal is based on DTW algorithm. Simultaneously the detected signals are allowed to pass through the channel estimation and equalization whose purpose is to reduce inter symbol interference to allow recovery of the transmit symbols. The equalized signal is then demodulated. The demodulated signals are received in the form of bits and from that bits symbol Error Rates (SER). Template data for DTW based matching is obtained by acquiring received frames for each modulation scheme. Because DTW works by matching the template with the signal under test, hence to improve the recognition performance we split the incoming test frame into multiple smaller sub frames. Then in the testing phase, we evaluate distances of the small sub frames with the large template and use a majority voting method to find out the modulation scheme in corresponding test frames.

\section{Experimental Results and Discussions}

The experimental results have been recorded under different transmit gain values i.e. $-20 \mathrm{~dB},-10 \mathrm{~dB}$ and $0 \mathrm{~dB}$ with varying distances i.e. $30 \mathrm{~cm}, 50 \mathrm{~cm}, 70 \mathrm{~cm}$ and $100 \mathrm{~cm}$ from the transmitter antenna to the receiver antenna for different modulation schemes. The modulation schemes that we have considered in our work are QPSK, 8-PSK, 16-QAM and 64-QAM. The observation results are recorded tabular form.

\subsection{Modulation Detection Under -20 db Transmit Gain}

Under -20 dB transmit gain, the QPSK modulation is detected correctly producing negligible symbol error rate as recorded in the Table I,

TABLE I. QPSK OBSERVED VALUES FOR -20 DECIBEL

\begin{tabular}{|c|c|c|c|c|}
\hline \multirow[b]{2}{*}{ SL No. } & \multicolumn{4}{|c|}{ Tx Gain under -20dB } \\
\hline & $\begin{array}{l}\text { Modulation } \\
\text { Type }(M=4)\end{array}$ & $\begin{array}{l}\text { Distance } \\
\text { (in cm) }\end{array}$ & SER & $\begin{array}{c}\text { Modulation } \\
\text { Detected }\end{array}$ \\
\hline 1 & \multirow{4}{*}{ QPSK } & 30 & 0.001500 & QPSK \\
\hline 2 & & 50 & 0.003000 & QPSK \\
\hline 3 & & 70 & 0.004000 & QPSK \\
\hline 4 & & 100 & 0.008500 & QPSK \\
\hline
\end{tabular}

In the next condition, we tried to detect 8-PSK under -20 dB transmit gain. The output is shown in Table II. From the output, it can be observed that, in some trials the detection shows a faulty modulation detection which means that under $-20 \mathrm{~dB}$ the received signal tends to distort and vary with noise resulting in false detection.

TABLE II. 8-PSK OBSERVED VALUES FOR -20 DECIBEL

\begin{tabular}{|c|c|c|c|c|}
\hline \multirow[b]{2}{*}{ SL No. } & \multicolumn{4}{|c|}{ Tx Gain under -20dB } \\
\hline & $\begin{array}{c}\text { Modulation } \\
\text { Type }(M=8)\end{array}$ & $\begin{array}{c}\text { Distance } \\
\text { (in cm) }\end{array}$ & $S E R$ & $\begin{array}{c}\text { Modulation } \\
\text { Detected }\end{array}$ \\
\hline 1 & \multirow{4}{*}{ 8-PSK } & 30 & 0.007500 & 8-PSK \\
\hline 2 & & 50 & 0.828000 & 16-QAM \\
\hline 3 & & 70 & 0.024500 & 8-PSK \\
\hline 4 & & 100 & 0.996000 & 64-QAM \\
\hline
\end{tabular}

Similarly, for the modulation detection of 16-QAM under $-20 \mathrm{~dB}$ transmit gain, the SER values are noted in Table III. In case of 16-QAM, the modulation is correctly detected producing a moderately low error rate.

TABLE III. 16-QAM OBSERVED VALUES FOR -20 DECIBEL

\begin{tabular}{|c|c|c|c|c|}
\hline \multirow[b]{2}{*}{ SL No. } & \multicolumn{4}{|c|}{ Tx Gain under -20dB } \\
\hline & $\begin{array}{c}\text { Modulation } \\
\text { Type }(M=16)\end{array}$ & $\begin{array}{l}\text { Distance } \\
\text { (in cm) }\end{array}$ & SER & $\begin{array}{c}\text { Modulation } \\
\text { Detected }\end{array}$ \\
\hline 1 & \multirow{4}{*}{ 16-QAM } & 30 & 0.052000 & 16-QAM \\
\hline 2 & & 50 & 0.057000 & 16-QAM \\
\hline 3 & & 70 & 0.223000 & 16-QAM \\
\hline 4 & & 100 & 0.670000 & 16-QAM \\
\hline
\end{tabular}

Also Table IV gives the value of SER for 64-QAM modulation. In this case, we have seen that DTW helps in detecting the particular type of modulation correctly. Though the signal is detected properly, from the tabulated value it can be observed that the error percentage increases on increasing the distance between the receiver and transmitter antenna. Therefore, according to our work the detection part is satisfied.

TABLE IV. 64-QAM OBSERVED VALUES FOR -20 DECIBEL

\begin{tabular}{|c|c|c|c|c|}
\hline \multirow[b]{2}{*}{ SL No. } & \multicolumn{4}{|c|}{ Tx Gain under -20dB } \\
\hline & $\begin{array}{l}\text { Modulation } \\
\text { Type }(M=64)\end{array}$ & $\begin{array}{c}\text { Distance } \\
\text { (in } \mathrm{cm})\end{array}$ & $S E R$ & $\begin{array}{c}\text { Modulation } \\
\text { Detected }\end{array}$ \\
\hline 1 & \multirow{4}{*}{ 64-QAM } & 30 & 0.552500 & 64-QAM \\
\hline 2 & & 50 & 0.933000 & 64-QAM \\
\hline 3 & & 70 & 0.750500 & 64-QAM \\
\hline 4 & & 100 & 0.985500 & 64-QAM \\
\hline
\end{tabular}




\subsection{Modulation Detection Under -10 db Transmit Gain}

The next modulation detection is carried out under the transmit gain of $-10 \mathrm{~dB}$. The procedure is similar to that of $-20 \mathrm{~dB}$ as explained above. The SER values for QPSK, 8PSK, 16-QAM and 64-QAM are listed in the Tables: V, VI, VII, and VIII respectively. The results that we have obtained under -10 dB transmit gain for QPSK seems to be similar as that of results obtained for $-20 \mathrm{~dB}$. For this modulation type, DTW detects the specific modulation without any faulty and less error. The detection for 8-PSK under $-10 \mathrm{~dB}$ gain sometimes, gives a faulty detection resulting in signal variation. On observing 16-QAM we have seen that, modulation has been detected in correct form with lower SER as compared to trials done under $-20 \mathrm{~dB}$ transmit gain. The result for 64-QAM is also shown in the following table as mentioned. It detects the appropriate modulation but contains more symbol error rate.

TABLE V. QPSK OBSERVED VALUES FOR -10 DECIBEL

\begin{tabular}{|c|c|c|c|c|}
\hline \multirow{2}{*}{ SL No. } & \multicolumn{4}{|c|}{ Tx Gain under -10dB } \\
\cline { 2 - 5 } & $\begin{array}{c}\text { Modulation } \\
\text { Type (M=4) }\end{array}$ & $\begin{array}{c}\text { Distance } \\
\text { (in } \text { cm })\end{array}$ & SER & $\begin{array}{c}\text { Modulation } \\
\text { Detected }\end{array}$ \\
\hline 1 & & 30 & 0.002500 & QPSK \\
\cline { 1 - 3 } 2 & \multirow{3}{*}{ QPSK } & 50 & 0.002000 & QPSK \\
\cline { 4 - 5 } & & 70 & 0.001500 & QPSK \\
\cline { 4 - 5 } 3 & & 100 & 0.003500 & QPSK \\
\hline 4
\end{tabular}

TABLE VI. 8-PSK OBSERVED VALUES FOR -10 DECIBEL

\begin{tabular}{|c|c|c|c|c|}
\hline \multirow[b]{2}{*}{ SL No. } & \multicolumn{4}{|c|}{ Tx Gain under -10dB } \\
\hline & $\begin{array}{c}\text { Modulation } \\
\text { Type }(M=8)\end{array}$ & $\begin{array}{c}\text { Distance } \\
\text { (in } \mathrm{cm})\end{array}$ & $S E R$ & $\begin{array}{c}\text { Modulation } \\
\text { Detected }\end{array}$ \\
\hline 1 & \multirow{4}{*}{ 8-PSK } & 30 & 0.005000 & 8-PSK \\
\hline 2 & & 50 & 0.006000 & 8-PSK \\
\hline 3 & & 70 & 0.878500 & 8-PSK \\
\hline 4 & & 100 & 1.000000 & 64-QAM \\
\hline
\end{tabular}

TABLE VII. 16-QAM OBSERVED VALUES FOR -10 DECIBEL

\begin{tabular}{|c|c|c|c|c|}
\hline \multirow{2}{*}{ SL No. } & \multicolumn{4}{|c|}{ Tx Gain under -10dB } \\
\cline { 4 - 5 } & $\begin{array}{c}\text { Modulation } \\
\text { Type (M=16) }\end{array}$ & $\begin{array}{c}\text { Distance } \\
\text { (in cm) }\end{array}$ & SER & $\begin{array}{c}\text { Modulation } \\
\text { Detected }\end{array}$ \\
\hline 1 & & 30 & 0.044000 & 16-QAM \\
\cline { 4 - 5 } 2 & \multirow{3}{*}{ 16-QAM } & 50 & 0.048500 & 16-QAM \\
\cline { 3 - 5 } & & 70 & 0.055000 & 16-QAM \\
\cline { 3 - 5 } & & 100 & 0.057500 & 16-QAM \\
\hline
\end{tabular}

TABLE VIII. 64-QAM OBSERVED VALUES FOR -10 DECIBEL

\begin{tabular}{|c|c|c|c|c|}
\hline \multirow[b]{2}{*}{ SL No. } & \multicolumn{4}{|c|}{ Tx Gain under -10dB } \\
\hline & $\begin{array}{c}\text { Modulation } \\
\text { Type }(M=64)\end{array}$ & $\begin{array}{l}\text { Distance } \\
\text { (in cm) }\end{array}$ & $S E R$ & $\begin{array}{c}\text { Modulation } \\
\text { Detected }\end{array}$ \\
\hline 1 & \multirow{4}{*}{ 64-QAM } & 30 & 0.192000 & 64-QAM \\
\hline 2 & & 50 & 0.470500 & 64-QAM \\
\hline 3 & & 70 & 0.680500 & 64-QAM \\
\hline 4 & & 100 & 0.754000 & 64-QAM \\
\hline
\end{tabular}

\subsection{Modulation Detection Under 0 db Transmit Gain}

The highest transmit gain that we have considered in this work is $0 \mathrm{~dB}$. Similarly, the SER values for QPSK, 8-PSK, 16-QAM, 64-QAM are listed in the Tables: IX, X, XI, XII respectively. Under $0 \mathrm{~dB}$ condition, QPSK modulation scheme is detected accurately. Similarly, 8-PSK is also detected effectively. 16-QAM shows better result i.e. it provides low SER under $0 \mathrm{~dB}$ as compared to other transmit gain. In case of 64-QAM, the modulation is detected correctly but with presence of more noise in the signal.

TABLE IX. QPSK OBSERVED VALUES FOR 0 DECIBEL

\begin{tabular}{|c|c|c|c|c|}
\hline \multirow[b]{2}{*}{ SL No. } & \multicolumn{4}{|c|}{ Tx Gain under OdB } \\
\hline & $\begin{array}{l}\text { Modulation } \\
\text { Type }(M=4)\end{array}$ & $\begin{array}{l}\text { Distance } \\
\text { (in cm) }\end{array}$ & SER & $\begin{array}{c}\text { Modulation } \\
\text { Detected }\end{array}$ \\
\hline 1 & \multirow{4}{*}{ QPSK } & 30 & 0.002000 & QPSK \\
\hline 2 & & 50 & 0.001500 & QPSK \\
\hline 3 & & 70 & 0.001000 & QPSK \\
\hline 4 & & 100 & 0.005000 & QPSK \\
\hline
\end{tabular}

TABLE X. 8-PSK OBSERVED VALUES FOR 0 DECIBEL

\begin{tabular}{|c|c|c|c|c|}
\hline \multirow[b]{2}{*}{ SL No. } & \multicolumn{4}{|c|}{ Tx Gain under 0dB } \\
\hline & $\begin{array}{c}\text { Modulation } \\
\text { Type }(M=8)\end{array}$ & $\begin{array}{l}\text { Distance } \\
\text { (in cm) }\end{array}$ & $S E R$ & $\begin{array}{c}\text { Modulation } \\
\text { Detected }\end{array}$ \\
\hline 1 & \multirow{4}{*}{ 8-PSK } & 30 & 0.882000 & 8-PSK \\
\hline 2 & & 50 & 0.007500 & 8-PSK \\
\hline 3 & & 70 & 0.012500 & 8-PSK \\
\hline 4 & & 100 & 0.009500 & 8-PSK \\
\hline
\end{tabular}

TABLE XI. 16-QAM OBSERVED VALUES FOR 0 DECIBEL

\begin{tabular}{|c|c|c|c|c|}
\hline \multirow[b]{2}{*}{ SL No. } & \multicolumn{4}{|c|}{ Tx Gain under OdB } \\
\hline & $\begin{array}{c}\text { Modulation } \\
\text { Type }(M=16)\end{array}$ & $\begin{array}{l}\text { Distance } \\
\text { (in } \mathrm{cm} \text { ) }\end{array}$ & $S E R$ & $\begin{array}{c}\text { Modulation } \\
\text { Detected }\end{array}$ \\
\hline 1 & \multirow{4}{*}{ 16-QAM } & 30 & 0.054000 & 16-QAM \\
\hline 2 & & 50 & 0.067500 & 16-QAM \\
\hline 3 & & 70 & 0.069000 & 16-QAM \\
\hline 4 & & 100 & 0.131000 & 16-QAM \\
\hline
\end{tabular}


TABLE XII. 64-QAM OBSERVED VALUES FOR 0 DECIBEL

\begin{tabular}{|c|c|c|c|c|}
\hline \multirow{2}{*}{ SL No. } & \multicolumn{4}{|c|}{ Tx Gain under 0dB } \\
\cline { 2 - 5 } & $\begin{array}{c}\text { Modulation } \\
\text { Type (M=64) }\end{array}$ & $\begin{array}{c}\text { Distance } \\
\text { (in cm) }\end{array}$ & SER & $\begin{array}{c}\text { Modulation } \\
\text { Detected }\end{array}$ \\
\hline 1 & & 30 & 0.229500 & 64-QAM \\
\hline \multirow{2nnnyy}{*}{2} & \multirow{2}{*}{ 64-QAM } & 50 & 0.512500 & 64-QAM \\
\cline { 3 - 5 } & & 70 & 0.418000 & 64-QAM \\
\cline { 3 - 5 } & & & & \\
\hline
\end{tabular}

\begin{tabular}{|c|c|c|c|c|}
\hline \multirow{2}{*}{ SL No. } & \multicolumn{4}{|c|}{ Tx Gain under OdB } \\
\cline { 2 - 5 } & $\begin{array}{c}\text { Modulation } \\
\text { Type }(M=64)\end{array}$ & $\begin{array}{c}\text { Distance } \\
\text { (in cm) }\end{array}$ & SER & $\begin{array}{c}\text { Modulation } \\
\text { Detected }\end{array}$ \\
\hline 4 & & 100 & 0.460000 & 64-QAM \\
\hline
\end{tabular}

Table XIII gives the overall comparisons between the different modulation schemes viz., QPSK, 8-PSK, 16-QAM and 64-QAM under different transmit gain $(-20 \mathrm{~dB},-10 \mathrm{~dB}$, $0 \mathrm{~dB})$ respectively.

TABLE XIII. COMPARISON BETWEEN QPSK, EPSK, 16-QAM, 64 QAM

\begin{tabular}{|c|c|c|c|c|c|c|c|c|c|c|c|c|}
\hline \multirow{3}{*}{$\begin{array}{c}\text { Distance } \\
\text { (in cm) }\end{array}$} & \multicolumn{12}{|c|}{ Symbol Error Rate under different Transmit Gain } \\
\hline & \multicolumn{4}{|c|}{$-20 d B$} & \multicolumn{4}{|c|}{$-10 d B$} & \multicolumn{4}{|c|}{$0 d B$} \\
\hline & QPSK & 8-PSK & 16-QAM & 64-QAM & QPSK & 8-PSK & 16-QAM & 64-QAM & QPSK & 8-PSK & 16-QAM & 64-QAM \\
\hline 30 & $\begin{array}{c}0.0015 \\
00\end{array}$ & $\begin{array}{c}0.0075 \\
00\end{array}$ & $\begin{array}{c}0.05200 \\
0\end{array}$ & $\begin{array}{c}0.55250 \\
0\end{array}$ & $\begin{array}{c}0.0025 \\
00\end{array}$ & $\begin{array}{c}0.0050 \\
00\end{array}$ & $\begin{array}{c}0.04400 \\
0\end{array}$ & $\begin{array}{c}0.19200 \\
0\end{array}$ & $\begin{array}{c}0.0020 \\
00\end{array}$ & $\begin{array}{c}0.8820 \\
00\end{array}$ & $\begin{array}{c}0.05400 \\
0\end{array}$ & $\begin{array}{c}0.22950 \\
0\end{array}$ \\
\hline 50 & $\begin{array}{c}0.0030 \\
00\end{array}$ & $\begin{array}{c}0.8280 \\
00\end{array}$ & $\begin{array}{c}0.05700 \\
0\end{array}$ & $\begin{array}{c}0.93300 \\
0\end{array}$ & $\begin{array}{c}0.0020 \\
00\end{array}$ & $\begin{array}{c}0.0060 \\
00\end{array}$ & $\begin{array}{c}0.04850 \\
0\end{array}$ & $\begin{array}{c}0.47050 \\
0\end{array}$ & $\begin{array}{c}0.0015 \\
00\end{array}$ & $\begin{array}{c}0.0075 \\
00\end{array}$ & $\begin{array}{c}0.06750 \\
0\end{array}$ & $\begin{array}{c}0.51250 \\
0\end{array}$ \\
\hline 70 & $\begin{array}{c}0.0040 \\
00\end{array}$ & $\begin{array}{c}0.0245 \\
00\end{array}$ & $\begin{array}{c}0.22300 \\
0\end{array}$ & $\begin{array}{c}0.75050 \\
0\end{array}$ & $\begin{array}{c}0.0015 \\
00\end{array}$ & $\begin{array}{c}0.8785 \\
00\end{array}$ & $\begin{array}{c}0.05500 \\
0\end{array}$ & $\begin{array}{c}0.68050 \\
0\end{array}$ & $\begin{array}{c}0.0010 \\
00\end{array}$ & $\begin{array}{c}0.0125 \\
00\end{array}$ & $\begin{array}{c}0.06900 \\
0\end{array}$ & $\begin{array}{c}0.41800 \\
0\end{array}$ \\
\hline 100 & $\begin{array}{c}0.0085 \\
00\end{array}$ & $\begin{array}{c}0.9960 \\
00\end{array}$ & $\begin{array}{c}0.67000 \\
0\end{array}$ & $\begin{array}{c}0.98550 \\
0\end{array}$ & $\begin{array}{c}0.0035 \\
00\end{array}$ & $\begin{array}{c}1.0000 \\
00\end{array}$ & $\begin{array}{c}0.05750 \\
0\end{array}$ & $\begin{array}{c}0.75400 \\
0\end{array}$ & $\begin{array}{c}0.0050 \\
00\end{array}$ & $\begin{array}{c}0.0095 \\
00\end{array}$ & $\begin{array}{c}0.13100 \\
0\end{array}$ & $\begin{array}{c}0.46000 \\
0\end{array}$ \\
\hline
\end{tabular}

TABLE XIV. SYSTEM EFFICIENCY TABLE

\begin{tabular}{|c|c|c|c|}
\hline \multirow{2}{*}{$\begin{array}{c}\text { Sl. } \\
\text { No. }\end{array}$} & \multicolumn{3}{|c|}{ Efficiency Table } \\
\cline { 2 - 4 } & $\begin{array}{c}\text { Total No. of } \\
\text { Trials }\end{array}$ & $\begin{array}{c}\text { No. of trials with } \\
\text { false detection }\end{array}$ & Percentage Accuracy \\
\hline & & 3 & $\begin{array}{c}100-\left(\frac{3}{48} \times 100\right) \\
=93.75 \%\end{array}$ \\
\hline
\end{tabular}

\section{Conclusion and Future Work}

Different sets of observation has been performed within a particular range between transmit and receive antenna. Table: I, Table: V and Table: IX, shows the observation of QPSK modulation under $-20 \mathrm{~dB},-10 \mathrm{~dB}$ and $0 \mathrm{~dB}$ respectively. Minimum symbol error rate (SER) is observed in QPSK modulation giving an accurate detection. Moving ahead to Table: II, Table: VI and Table: $X$, the modulation detection under the same transmit gain values as stated earlier gives the observations performed for 8-PSK modulation detection where the received signal starts showing faulty detection for some cases with high SER under low transmit gain and producing low SER under high transmit gain. Table: III, Table: VII and Table: XI shows the SER values for 16QAM with proper detection and different ranges of SER values taking the transmit gain accordingly. The SER values of modulation detection for 64-QAM are listed in Table: IV, Table: VIII, Table: XII respectively showing proper detection with moderate error rate. Table: XIII shows the overall accuracy of the DTW system under different modulation schemes. The accuracy of the system is found to be $93.75 \%$ approximately.

Future works will include more modulation scheme in the modulation detection, improving synchronization to further to decreases the bit error rate, working using bulk samples in the modulation detection and working with high precision software defined radio.

\section{Acknowledgment}

The authors would like to express gratitude to the faculty members of the Department of Electronics and Communication Technology, Gauhati University for their guidance and for their precious comments which further 
improved the quality of this work. Further, the authors are thankful to the MHRD-TEQIP III.

\section{References}

[1] S. K. Vasudevan, R. Sivaraman, and Z.C. Alex, "Software Defined Radio Implementation (With simulation \& analysis)" International Journal of Computer Applications, pp. 0975-8887, 2010

[2] B. B. Godbole and D. S. Aldar. "Performance improvement by changing modulation methods for software defined radios". arXiv. 1212-0114, 2012.

[3] C.Y. Chen, F. Hsun Tseng, K. Chang, H. Chao and J. Chen "Reconfigurable software defined radio and its applications."13, no. 1, pp. 29-38, 2010.

[4] A. A. Tabassam, F. Azmat Ali, S. Kalsait and M. Uzair Suleman. "Building software-defined radios in MATLAB simulink-A step towards cognitive radios." In UkSim 13th International Conference on Computer Modelling and Simulation, pp. 492-497, 2011.

[5] M. A. Hannan, M. Tariqul Islam, S. Abdul Samad and A. Hussain "Modulation techniques for RFID transceiver using software defined radio." International Journal of Innovative Computing, Information and Control 8, no. 10 A , pp. 6667-6692, 2012

[6] K. Mehta "A review on adaptive modulation recognition techniques" International Journal of Engineering Research and Technology (IJERT), 2012.

[7] R. R. Bhambare and R. D. Raut. "A survey on digital modulation techniques for software defined radio applications." International. Journal Computer Network Wireless Communication.(IJCNWC), no. 3, pp. 292-299, 2013.

[8] R. Sivappagari and C. Mohan. "Software Defined Radio using Digital Modulation Techniques-A MATLAB SIMULINK Approach." In Proceedings of International Academic Conference on Electrical, Electronics and Computer Engineering. 2013.

[9] M. A. Kumar and P. Ramesh. "A Novel Design in Digital Communication using Software Defined Radio." International Journal of Engineering Trends and Technology, April 4, no. 4, pp. 1096-1100, 2013

[10] N. Arya, K. Sharma and G. Singh. "Software defined radio for wireless networks." In International Journal of Recent Research Aspects ISSN, vol. 1, pp. 25-29, 2014.

[11] G. P. Raosaheb and R. R. Bhambare. "Adaptive OFDM Modulation Used For SDR." International Journal Of Technology Enhancements And Emerging Engineering Research 2, no. 8, 2014.

[12] B. S. K. Reddy and B. Lakshmi. "Adaptive modulation and coding for mobile-WiMAX using SDR in GNU radio." In International Conference on Circuits, Systems, Communication and Information Technology Applications (CSCITA), pp. 173-178, 2014.

[13] J. R. Machado-Fernández, "Software defined radio: Basic principles and applications." Facultad de Ingeniería 24, no. 38, pp. 79-96, 2015.

[14] D. F. Macedo, D. Guedes, L. F. M. Vieira, M. A. M. Vieira and Michele Nogueira. "Programmable networks-From softwaredefined radio to software-defined networking." IEEE communications surveys \& tutorials 17 , no. 2, pp. 1102-1125, 2015.

[15] Y. Lu, X. Su, J. Zeng, L. Rong, C. Yang and Xibin Xu. "Software defined radio access network in 5G mobile network." In 10th International Conference on Communications and Networking in China (ChinaCom), pp. 132-136, 2015.

[16] Z. El. A. Ismaili, W. Ajib, Omar A. Yeste-Ojeda, and René Landry. "Implementation of adaptive modulation for $\mathrm{A} / \mathrm{G}$ communication system using ZeptoSDR." In IEEE/AIAA 34th Digital Avionics Systems Conference (DASC), pp. 2C5-1, 2015.

[17] M. Darmetko, S. Kozłowski, K. Kurek, J. Skarzyński, J. Modelski, K. Szczygielska and Marcin Stolarski. "Adaptive communication system using software defined radio." In International Microwave and RF Conference (IMaRC), pp. 185-187, 2015.

[18] S. Singh, G. Mushtaq, N. K. Tiwari and A. P. Singh. "Cognitive Radio With Software Defined Radio and Mimo for Future Generation Wireless Communication." Journal of Computer Science \& Systems Biology, vol 8, no. 3, pp. 166, 2015.
[19] N. Marriwala, O. P. Sahu and A. Vohra. "Design of a hybrid reconfigurable Software Defined Radio transceiver based on frequency shift keying using multiple encoding schemes." Egyptian Informatics Journal 17, no. 1, pp. 89-98, 2016.

[20] J. Skarzynski, M. Darmetko, S. Kozlowski and K. Kurek. "SDR implementation of the receiver of adaptive communication system." Radio Science 51, no. 4, pp. 344-351, 2016.

[21] M. V. Kiresur and S. Sandya. "Reconfigurable software defined radio modem for Personal Area Network." In International Conference on Wireless Communications, Signal Processing and Networking (WiSPNET), pp. 1431-1436, 2017

[22] E. Zhang, J. Zambrano, A. Amrhar, R. Landry and W. Ajib. "Design and implementation of a Wideband Radio using SDR for avionic applications." In Integrated Communications, Navigation and Surveillance Conference (ICNS), pp. 2D2-1, 2017.

\section{Creative Commons Attribution License 4.0 (Attribution 4.0 International, CC BY 4.0)}

This article is published under the terms of the Creative Commons Attribution License 4.0 https://creativecommons.org/licenses/by/4.0/deed.en US 